\title{
ЭПИДЕМИЧЕСКИЙ ПОТЕНЦИАЛ COVID-19 В ОМСКОЙ ОБЛАСТИ И ОЦЕНКА ВОЗМОЖНОГО ВЛИЯНИЯ ПРОТИВОЭПИДЕМИЧЕСКИХ МЕРОПРИЯТИЙ
}

\author{
Блох А.И. ${ }^{1,2}$, Пеньевская Н.А. ${ }^{1,2}$, Рудаков Н.В. ${ }^{1,2}$, Лазарев И.И. ${ }^{2}$
}

${ }_{1}^{1}$ ФБУН «Омский НИИ природно-очаговых инфекций» Роспотребнадзора, г. Омск, Россия

${ }^{2}$ ФББОУ ВО «Омский государственный медицинский университет» Минздрава России, г.

Омск, Россия

\section{РЕЗЮМЕ}

Цель. Изучить распространение COVID-19 среди населения Омской области на протяжении первых 115 дней эпидемического неблагополучия на фоне противоэпидемических мероприятий.

Материалы и методы. Выполнено описательное эпидемиологическое исследование на основе данных ФБУЗ «Центр гигиены и эпидемиологии в Омской области» по официальному учёту и эпидемиологическому расследованию выявленных случаев COVID-19 на территории Омской области за период с 27 марта по 19 июля 2020 года. Для оценки потенциала COVID-19 к распространению рассчитаны экспоненциальный темп прироста (r), базовый показатель репродукции $\left(\mathrm{R}_{0}\right)$, эффективный показатель репродукции $\left(\mathrm{R}_{\mathrm{t}}\right)$, ожидаемый естественный размах эпидемии и порог коллективного иммунитета. Обработка данных выполнена с использованием MS Excel 2010. Построение картограммы проводилось в приложении QGIS 3.12-Bukuresti в системе координат EPSG: 3576.

Результаты. За период с 27 марта по 19 июля 2020 года на территории Омской области было зарегистрировано 5503 случая COVID-19, показатель заболеваемости составил $285,6 \%$ ооо (95\% ДИ 278,1 $\div 293,2)$, летальность по завершенным случаям - 1,5\%, по выявленным случаям - 0,9\%. Наиболее активное распространение COVID-19 отмечено в г. Омске и 5 из 32 районов области (Калачинском, Нововаршавском, Русско-Полянском, Москаленском, Азовском немецком национальном).

Наименее вовлечены в эпидемический процесс возрастные группы от 0 до 19 лет и 2029 лет. Наиболее уязвимы мужчины 55-69 лет и женщины 50-64 лет. В структуре клинических форм COVID-19 на протяжении периода наблюдения отмечено уменьшение доли выявляемых бессимптомных форм и увеличение доли пневмоний. Установлено многократное увеличение числа внебольничных пневмоний в июне и июле 2020 г. по сравнению со среднемноголетними значениями 2017-2019 гг.

На фоне проводимых противоэпидемических мероприятий экспоненциальный темп прироста кумулятивного количества случаев COVID-19 составлял 6,6\% в сутки, $\mathrm{R}_{0}$ - 1,4-1,5, $\mathrm{R}_{\mathrm{t}}-1,18$, порог коллективного иммунитета - 28,6\%. Ожидаемый размах эпидемии при условии продолжения действия ограничительных мер может достигнуть 58,0\% переболевшего населения.

Заключение. Потенциал COVID-19 к распространению среди населения Омской области подавлен недостаточно. Уменьшение количества выявляемых вирусоносителей, не полное выявление COVID-19 среди заболевших внебольничными пневмониями создают дополнительные риски для скрытого распространения инфекции и осложнения эпидемической ситуации. Сохранение ограничительных мероприятий и превышение порога 
коллективного иммунитета (28,6\% населения) позволит значительно снизить риски усиления распространения COVID-19 в Омской области.

Ключевые слова: эпидемиология, COVID-19, экспоненциальный темп прироста, показатель репродукции, ожидаемый естественный размах эпидемии, порог коллективного иммунитета.

\title{
Конфликт интересов
}

Авторы заявляют об отсутствии конфликта интересов.

\section{Источник финансирования}

Исследование не имело спонсорской поддержки.

\section{EPIDEMIC POTENTIAL OF COVID-19 IN OMSK REGION AND ASSESSMENT OF THE IMPACT OF ANTI-EPIDEMIC MEASURES}

\author{
Blokh A.I. ${ }^{1,2}$, Pen'evskaya N.A. ${ }^{1,2}$, Rudakov N.V. ${ }^{1,2}$, Lazarev I.I. ${ }^{2}$ \\ ${ }^{1}$ Omsk Research Institute of Natural Focal Infections, Omsk, Russian Federation \\ ${ }^{2}$ Omsk State Medical University, Ministry of Healthcare of Russian Federation, Omsk, Russian \\ Federation
}

Aim. To study the spread of COVID-19 among the population of the Omsk region during the first 115 days of the epidemic during anti-epidemic measures.

Materials and methods. A descriptive epidemiological study was carried out based on data from the Center for Hygiene and Epidemiology in the Omsk Region on the official registration and epidemiological investigation of detected cases of COVID-19 in the Omsk Region for the period from March 27 to July 19, 2020. To assess the potential of COVID-19 to spread, the following indicators were calculated: exponential growth rate (r), basic reproduction number (R0), effective reproduction number $(\mathrm{Rt})$, expected natural epidemic size and herd immunity threshold. Data processing was performed using MS Excel 2010. The cartogram was built using the QGIS 3.12Bukuresti application in the EPSG: 3576 coordinate system.

Results. For the period from March 27 to July 19, 2020, 5503 cases of COVID-19 were registered in the Omsk region, the incidence rate was $285.6 \%$ ooo (95\% CI $278.1 \div 293.2)$, the casefatality rate for completed cases was $1,5 \%$, for identified cases $-0.9 \%$. The most active spread of COVID-19 was noted in Omsk and 5 out of 32 districts of the region (Kalachinsky, Novovarshavsky, Russko-Polyansky, Moskalensky, Azov German national).

The least involved in the epidemic process were the age groups from 0 to 19 years old and 2029 years old. Among the most affected groups were 55-69 years old males and 50-64 years old females. In the structure of clinical forms of COVID-19 during the observation period, a decrease in the proportion of detected asymptomatic forms and an increase in the proportion of pneumonia were noted. A multiple increase in the number of community-acquired pneumonia in June and July 2020 compared to the average long-term values for 2017-2019 was established.

During the ongoing anti-epidemic measures, the exponential growth rate of the cumulative number of COVID-19 cases was $6.6 \%$ per day, $\mathrm{R}_{0}-1.4-1.5$, Rt - 1.18, herd immunity threshold $28.6 \%$. The expected size of the epidemic in case of sustained anti-epidemic measures can reach $58.0 \%$ of the population.

Conclusion. The potential for COVID-19 to spread among the population of the Omsk region is not sufficiently suppressed. A decrease in the number of detected virus carriers, incomplete 
detection of COVID-19 among patients with community-acquired pneumonia introduced additional risks for the latent spread of infection and complications of the epidemic situation. Maintaining restrictive measures and increasing the proportion of the immune population (over 28.6\% population) may significantly reduce the risks of increasing the spread of COVID-19 in the Omsk region.

Key words: epidemiology, COVID-19, exponential growth rate, reproductive number, final size of epidemic, herd immunity threshold.

\section{Conflict of interest}

The authors declare no conflicts of interest.

\section{Source of financing}

The study was not sponsored.

\section{Благодарности}

Авторы выражают признательность сотрудникам ФБУЗ «Центр гигиены и эпидемиологии в Омской области»: главному врачу Никитину С.В., заведующей отделом обеспечения эпидемиологического надзора Михайловой O.А., а также Федорову А.С. за оказанную помощь по сбору материалов для данного исследования.

\section{Ведение}

Новая коронавирусная инфекция COVID-19, впервые выявленная в городе Ухань в конце 2019 года, признана ВОЗ имеющей международное значение ситуацией в области здравоохранения [1]. К 20 июля 2020 г. COVID-19 был выявлен у 14348858 человек и унёс жизни 603691 из них, при этом на долю Российской Федерации приходилось 777486 случаев и 12427 смертей соответственно [2]. Сложившаяся сегодня ситуация представляет уникальные возможности для эпидемиологического изучения распространения нового патогена, к которому существенная часть населения не имеет иммунитета.

Распространение COVID-19 в Омской области происходило на фоне противоэпидемических мероприятий. Первые случаи COVID-19 на территории Омской области выявлены 27 марта 2020 г., то есть на месяц позже, чем в г. Москва. Еще за 10 дней до выявления первых инфицированных в Омской области указом губернатора был введен режим повышенной готовности с 
соответствующими мерами по недопущению завоза и распространения новой коронавирусной инфекции, сохраняющийся до 4 августа. С 1 апреля в Омской области установлен особый режим самоизоляции, включающий перевод образовательных организаций на дистанционный режим работы, запрет массовых мероприятий, закрытие дошкольных учреждений, приостановление деятельности не системообразующих организации и предприятий, ограничение передвижения внутри и за пределами г.Омска и прочее. Частичное ослабление полного режима самоизоляции было начато 4 июня 2020 г.

Цель исследования: изучить распространение COVID-19 среди населения Омской области на протяжении первых 115 дней эпидемического неблагополучия на фоне противоэпидемических мероприятий.

\section{Материалы и методы}

Материалом для настоящего описательного эпидемиологического исследования послужили данные ФБУЗ «Центр гигиены и эпидемиологии по Омской области» по официальному учёту и эпидемиологическому расследованию выявленных случаев COVID-19 на территории Омской области за период с 27 марта (выявление первых инфицированных) по 19 июля 2020 года. Все выявленные случаи были подтверждены методом ПЦР в одной из лабораторий, действующих на территории региона: ФБУН «Омский НИИ природно-очаговых инфекций» Роспотребназдора или ФБУЗ «Центр гигиены и эпидемиологии в Омской области» в соответствии с утверждённой маршрутизацией. По каждому случаю COVID-19 собиралась рутинная информация, в том числе о поле и возрасте, предполагаемом месте и источнике заражения (для местных случаев), дате появления симптомов, клиническом течении на момент регистрации.

Кроме того, в исследовании использовали данные таких интернетpeсурсов, как стопкоронавирус.pф, mzdr.omskportal.ru, а также официальных интернет-страниц оперативных штабов по предупреждению завоза и распространения новой коронавирусной инфекции в соседних с Омской областью регионов РФ и Республики Казахстан. 
Для оценки исходного потенциала COVID-19 к распространению на территории Омской области вычислен базовый показатель репродукции $\left(\mathrm{R}_{0}\right), \mathrm{a}$ для оперативной оценки ситуации использовали эффективный показатель репродукции $\left(\mathrm{R}_{\mathrm{t}}\right)$. Методика расчёта базового показателя репродукции описана Wallinga J., Lipsitch M. [3] и предполагает знание величин экспоненциального темпа прироста (intrinsic growth factor) и серийного интервала - СИ. Экспоненциальный темп прироста (r) вычисляли с помощью простой регрессии Пуассона [3] из кумулятивного числа случаев за период с начала регистрации до 15 апреля - даты, на которую коэффициент детерминации был наибольшим, составляя 93,3\%. Оценку СИ проводили по литературным данным.

Серийный интервал является легко вычисляемой альтернативой времени генерации - промежутка между заражением двух человек в единой эпидемической цепочке. Более длительный серийный интервал является благоприятным прогностическим признаком для системы эпидемиологического надзора: он фактически означает больший запас времени на проведение эпидемиологических расследований и необходимое реагирование [4]. Серийный интервал COVID-19 сегодня оценивается в 4-8 дней, с большинством оценок около 4 дней. В расчетах мы использовали оценку в 3,96 (95\% ДИ 3,534,39) дня из крупнейшего исследования Park M. et al. (2020) [5] с допущением двух распределений для моделирования СИ в связи с тем, что $\mathrm{R}_{0}$, вычисленный из дельта-распределённого серийного интервала, считается наиболее консервативной оценкой, в то время как $\mathrm{R}_{0}$ из экспоненциально распределённого СИ может считаться «средней» оценкой [3]. От величины $\mathrm{R}_{0}$ зависят такие прогностические эпидемиологические показатели, как ожидаемый естественный размер эпидемии (epidemic final size) и порог коллективного иммунитета (herd immunity threshold), которые вычисляли по Miller J.C. (2012) и Rodpothong P, Auewarakul P. (2012) соответственно [6, 7]. Оценку $\mathrm{R}_{\mathrm{t}}$ проводили по методике Cori A.et al. (2013) на основе количества выявленных случаев COVID-19 за прошедшие 7 дней [8]. В целом показатели репродукции выше 1 свидетельствуют о наличии (сохранении) потенциала 
инфекционного заболевания к эпидемическому распространению в конкретной популяции, в то время как показатели репродукции меньше 1 - об отсутствии такого потенциала [3]. Ретроспективные данные о количестве зарегистрированных экстренных извещений с установленным диагнозом «внебольничная пневмония» за 2017-2019 гг. были подвергнуты регрессионному анализу с помощью множественной регрессии, в которой сезонный компонент задавался синусоидальной функцией [9], а оперативные данные за 2020 год представлены без изменений.

Обработка данных выполнена с использованием MS Excel 2010. Построение картограммы проводили в приложении QGIS 3.12-Bukuresti в системе координат EPSG: 3576.

\section{Результаты}

За период с 27 марта по 19 июля 2020 года на территории Омской области было зарегистрировано 5503 случаев COVID-19, из которых 52 завершились смертью и 3217 выздоровлением. Распространение COVID-19 по территории области началось с семейного кластера из 3 завозных случаев из числа лиц, прибывших из поездки в Объединенные Арабские Эмираты, а к концу анализируемого периода было выявлено 162 завозных случая COVID-19. Местная передача отмечена немногим позднее: 30 марта выявлен кластер из 3 заболевших, не имевших в анамнезе выездов с территории области. Экспоненциальный темп прироста кумулятивного количества случаев COVID19 за период с 27 марта по 19 июля 2020 г. составлял 6,6\% в сутки (рис. 1). 


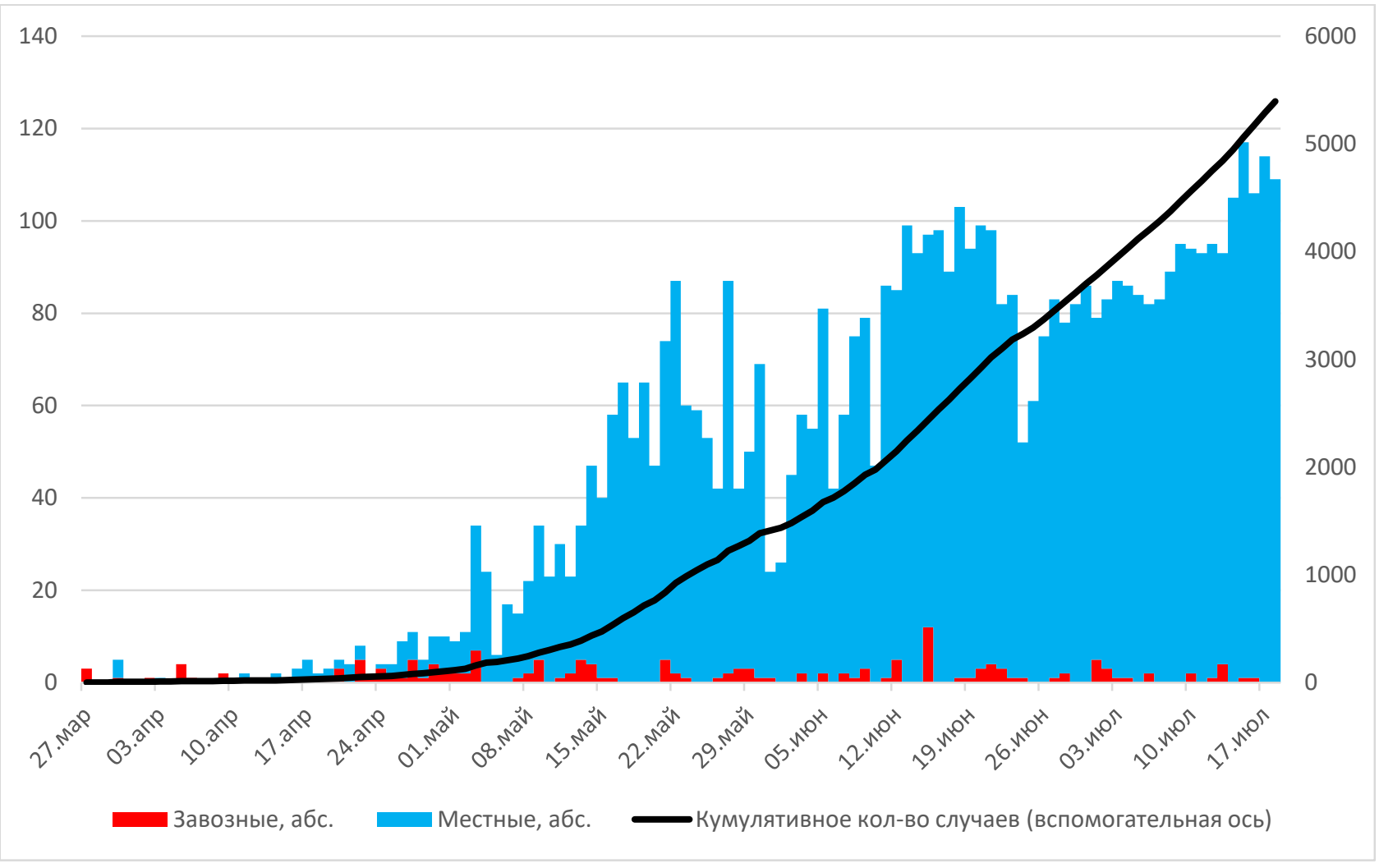

Рис. 1. Динамика выявления новых случаев COVID-19 в Омской области в зависимости от предполагаемого места заражения за период 27.03.20-19.07.20 гг. (абс.).

Fig. 1. Epidemic curve of COVID-19 in Omsk region by assumed place of infection during 27.03.20-19.07.20 (abs.).

Первый летальный исход у пациента с COVID-19 зарегистрирован 24 апреля. Оперативные оценки летальности, произведённые на основе завершённых случаев COVID-19, в мае достигали $13,7 \%$, а на основе выявленных случаев $-3,1 \%$. К июлю оба показателя относительно стабилизировались на уровне $1,5 \%$ и $0,9 \%$ соответственно (рис. 2). 


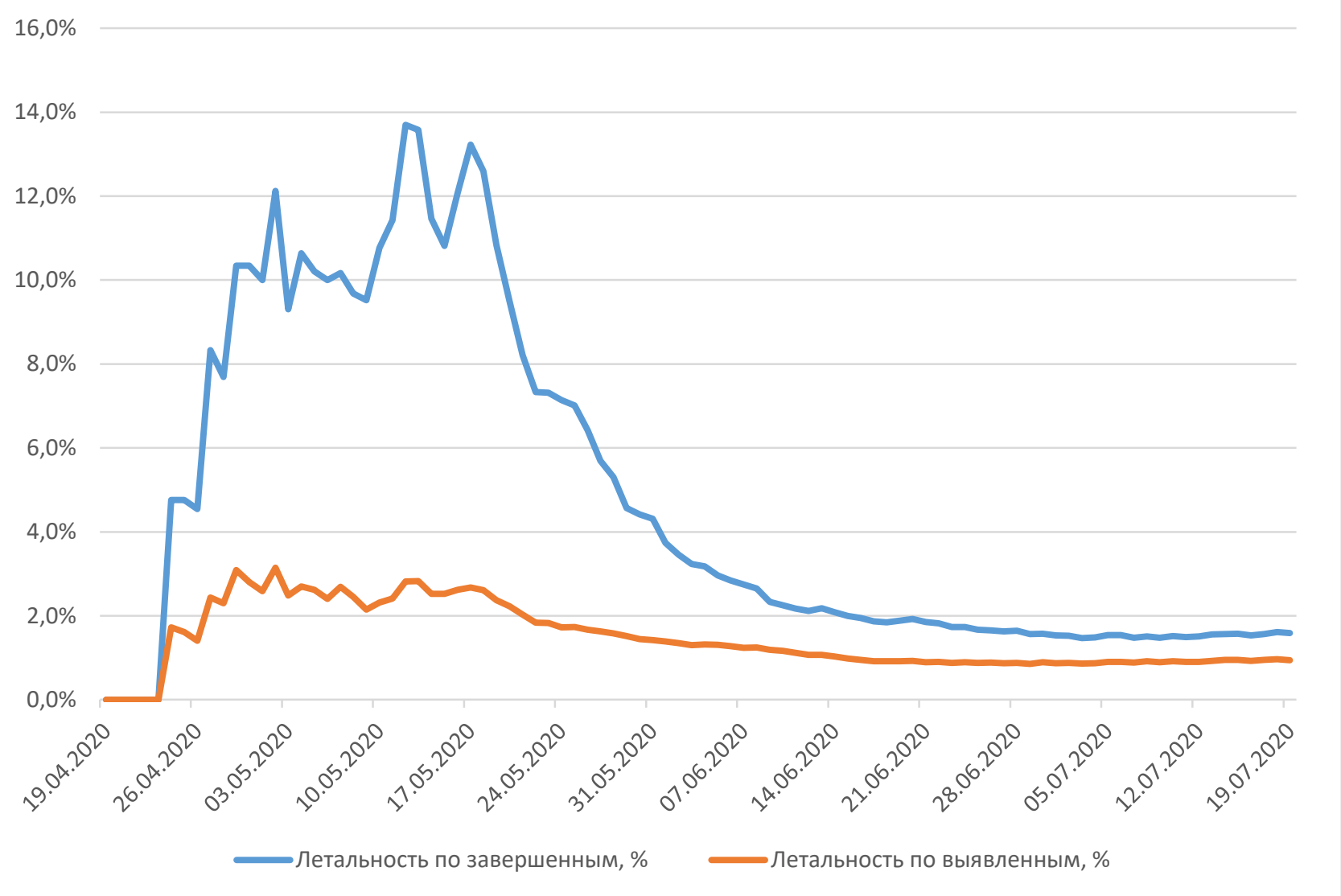

Рис. 2. Оценка летальности COVID-19 в Омской области (в \%).

Fig. 2. Case fatality rate of COVID-19 in Omsk region (\%).

Территориальное распределение случаев COVID-19 по состоянию на 20.07.20 г. характеризовалось выраженной неравномерностью: так 76,4\% (4205/5503) случаев выявлено в г. Омске, 4,5\% (245/5503) в Омском, 2,6\% $(144 / 5503)$ в Калачинском, 1,7\% (94/5503) в Москаленском, 1,5\% (85/5503) в Азовском немецком национальном, 1,4\% (78/5503) в Нововаршавском, 1,3\% (71/5503) в Марьяновском, 1,3\% (69/5503) в Таврическом и 1,1\% (63/5503) в Русско-Полянском муниципальном районе. На остальные районы приходилось менее $1 \%$ выявленных случаев. К концу анализируемого периода в областной структуре заболеваний COVID-19 отмечено снижение доли случаев, зарегистрированных в г. Омске, что свидетельствует об активизации эпидемического процесса в районах области.

Кумулятивный показатель заболеваемости населения Омской области COVID-19 составил 285,6 (95\% ДИ 278,1 293,2$)$ на 100000 населения, и был 
превышен в Омске - 364,2 (95\% ДИ 353,2 $\div 375,2)$, а также в муниципальных районах: Калачинском - 370,6 (95\% ДИ 310,1 431,2) на 100000 населения,

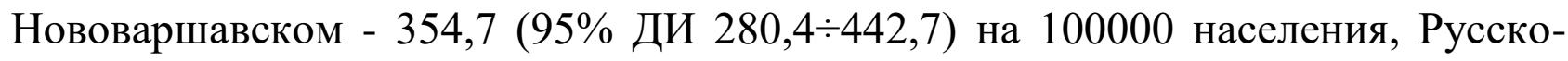
Полянском - 360,0 (95\% ДИ 276,6־460,6) на 100000 населения, Москаленском $337,9$ (95\% ДИ 273,1 413,5$)$ на 100000 населения и Азовском немецком

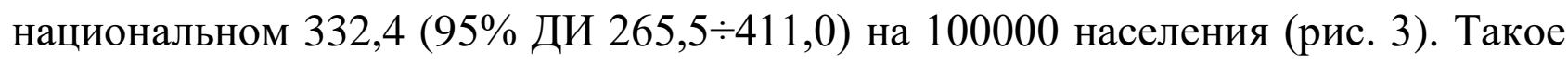
территориальное распределение случаев может объясняться более интенсивным движением товаров и пассажиров в направлении восток-запад через Омск, а также из Омска на юг в Казахстан и обратно. В граничащих с Омской областью регионах России и Казахстана на 20.07.20 г. отмечены более высокие показатели заболеваемости населения COVID-19: Новосибирская область 292,5 (95\% ДИ 286,2 $\div 298,9)$, Томская область 323,6 (95\% ДИ

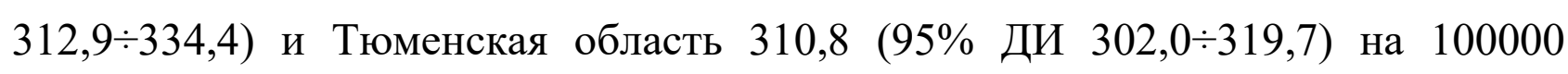
населения соответственно, Северо-Казахстанская область - 383,9\%ооо (95\% ДИ

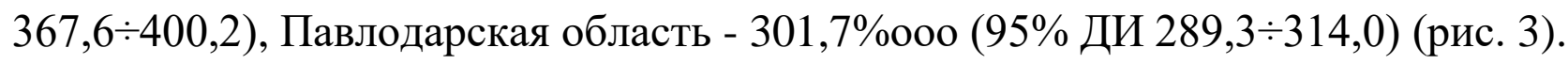


Омск

2 Азовский

3 Большереченский

4 Большеуковский

5 Горьковский

6 Знаменский

7 Исилькульский

8 Калачинский

9 Колосовский

10 Кормиловский

11 Крутинский

12 Любинский

13 Марьяновский

14 Москаленский

15 Муромцевский

16 Называевский

17 Нижнеомский

18 Нововаршавский

19 Одесский

20 Оконешниковский

21 Омский

22 Павлоградский

23 Полтавский

24 Русско-Полянский

25 Саргатский

26 Седельниковский

27 Таврический

28 Тарский

29 Тевризский

30 Тюкалинский

31 Усть-Ишимский

32 Черлакский

32 Шербакульский

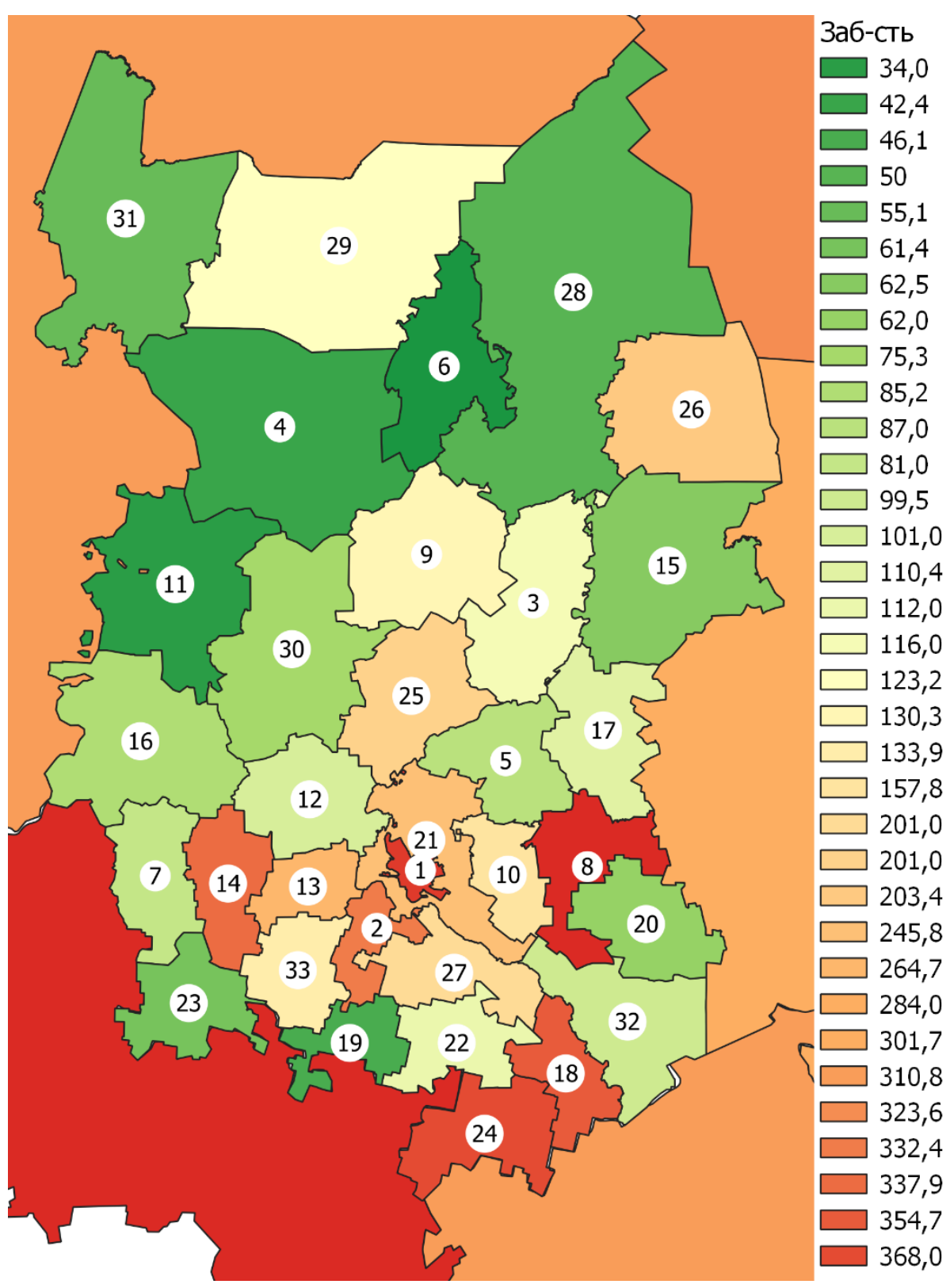

Рис. 3. Территориальное распределение заболеваемости COVID-19 населения Омской области на 20.07 .20 г. (на 100000 населения соответствующей территории).

Примечание: к востоку от Омской области расположена Новосибирская область, к северо-западу - Тюменская область, на северо-востоке - Томская область. К юго-западу - Северо-Казахстанская область Республики Казахстан, к юго-востоку - Павлодарская область Республики Казахстан.

Fig. 3. Spatial distribution of COVID-19 morbidity in Omsk region as of 20.07.20 (per 100000 pop.). 
В результате анализа структуры заболевших COVID-19 по полу и возрасту установлено, что за анализируемый период на долю мужчин пришлось 44,1\% (2463/5584) случаев, по которым имелась соответствующая информация. Медианный возраст заразившихся COVID-19 мужчин составил 45 (32; 60) лет, женщин - 52 (39; 64) лет соответственно. Распределение больных COVID-19 по возрасту и полу за анализируемый период несколько отличалась от половозрастной структуры населения Омской области (рис. 4). Так удельный вес лиц молодого возраста (до 19 лет включительно) в структуре случаев COVID-19 составлял 5,0\% и 4,8\% против 25,9\% и 24,7\% для мужчин и женщин соответственно в структуре всего населения, что свидетельствует об относительно малой вовлеченности указанных возрастных групп в эпидемический процесс COVID-19 на территории Омской области. Возможным объяснением является своевременное закрытие детских дошкольных учреждений и перевод образовательных учреждений на удалённый режим работы, что привело к разобщению коллективов несовершеннолетних жителей Омской области и затруднило их заражение. С этим согласуется и несколько меньший удельный вес возрастных групп 20-29 лет в структуре случаев COVID-19, составивший 10,9\% и 9,4\% против 12,4\% и 11,9\% соответственно, что может быть так же связано с переводом колледжей и ВУЗов на удалённый режим работы.

Доля возрастных групп 55-69 лет у мужчин и 50-64 лет у женщин в структуре случаев COVID-19 особенно значима: она составляла 28,9\% и 39,1\% против $19,8 \%$ и $25,7 \%$ соответственно в структуре всего населения области. 


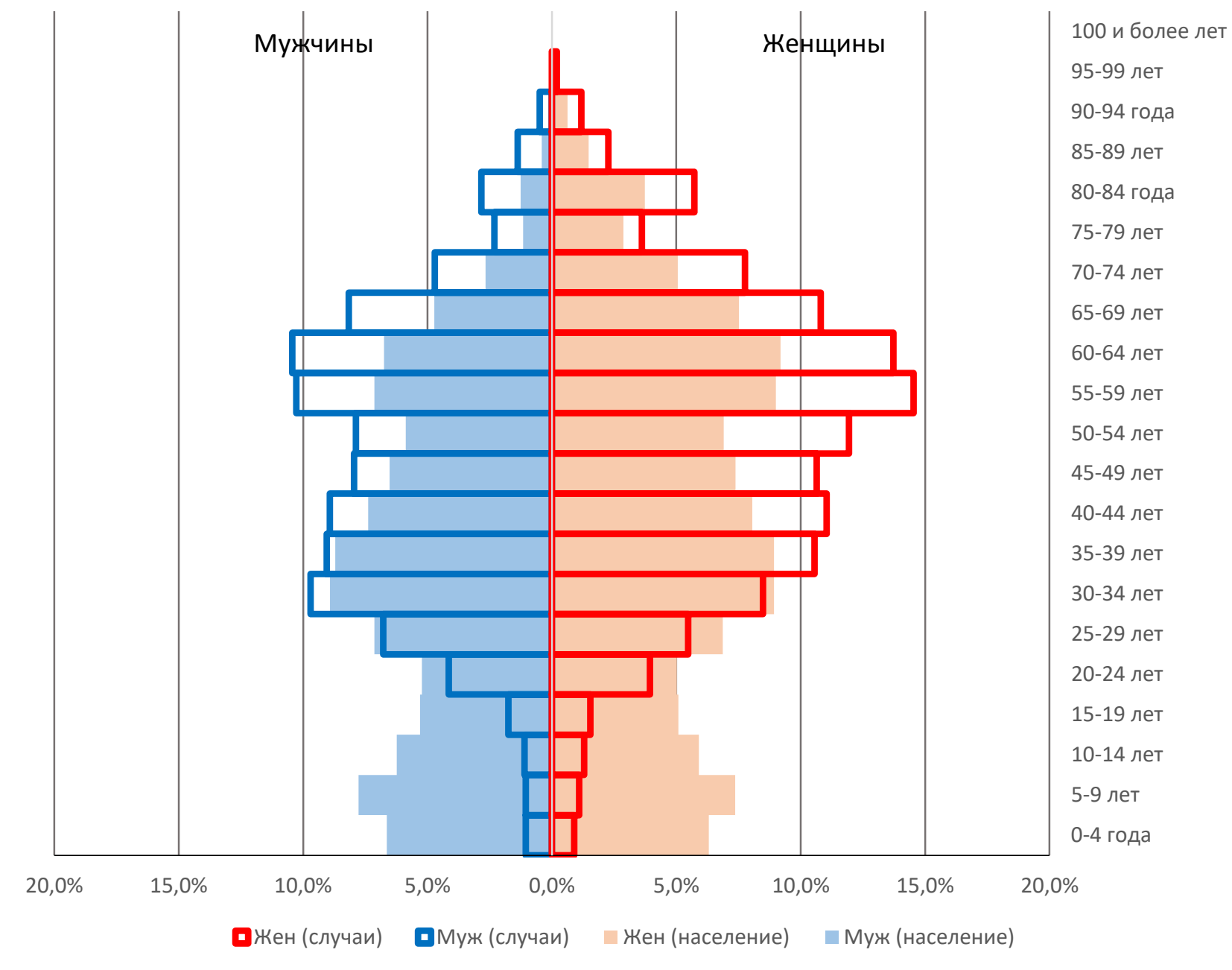

Рис. 4. Распределение случаев COVID-19 по полу и возрасту в период 27.03.20-19.07.20 гг. в сравнении с половозрастной структурой населения Омской области (в \%).

Fig. 4. Age and sex distribution of COVID-19 cases compared to age and sex distribution of population in Omsk region during 27.03.20-19.07.20 (\%).

Структура клинических форм COVID-19 на протяжении анализируемого периода наблюдения претерпевала ряд изменений (рис. 5). В течение первых недель эпидемии, когда число вновь выявленных случаев было менее или равно 10-20 за неделю, преобладали бессимптомные формы или заболевания с клиникой ОРВИ. По мере увеличения количества новых случаев COVID-19 доля «ковидных» ОРВИ снижалась, и, в мае-июле, как правило, не превышала $10 \%$ среди всех выявленных за неделю. Удельный вес бессимптомных форм, составляя в период с 27 апреля по 24 мая 60-70\%, затем опустился ниже 50\%, 
достигая в отдельные недели 30\%. Параллельно отмечался рост доли «ковидных» пневмоний, которая в середине июня (с 15 по 21 июня) составила $61,5 \%$.

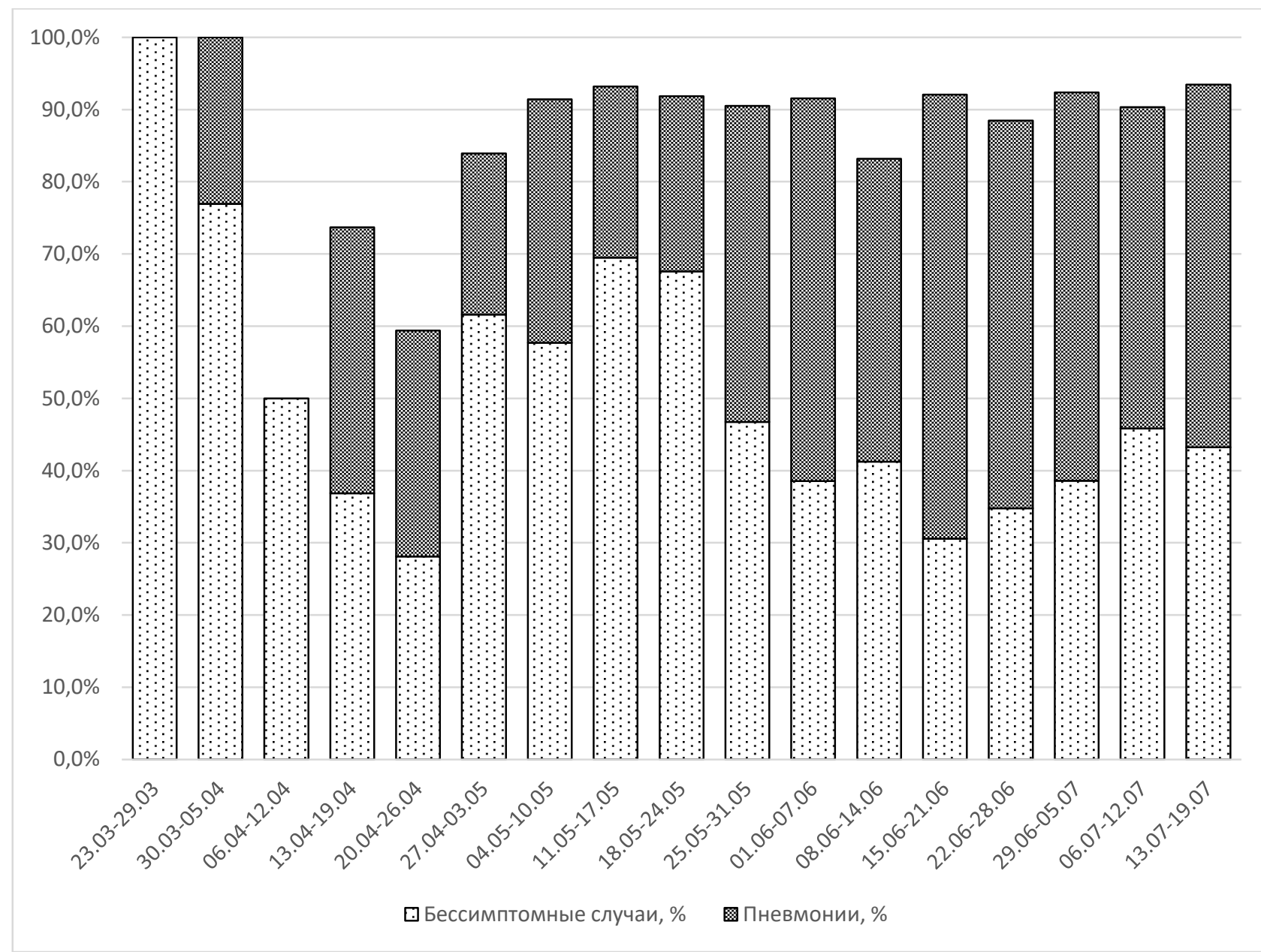

Рис. 5. Структура клинических проявлений COVID-19 на момент выявления случаев (в \%).

Fig. 5. Clinical structure of COVID-19 cases (\%).

На рисунке 6 представлена сглаженная кривая среднемноголетней внутригодовой динамики эпидемического процесса внебольничных пневмоний в Омской области в 2017-2019 гг. (черная линия) в сопоставлении с оперативными данными за 2020 г. Заметное расхождение многолетней тенденции с данными 2020 года начинается с первых чисел мая. Вместо ожидаемого снижения наблюдается быстрый рост среднего количества экстренных извещений, поданных за неделю, по которым окончательным диагнозом указана «внебольничная пневмония». К концу анализируемого 
периода превышение среднемноголетних показателей достигло 9 раз, что не удается объяснить регистрируемыми случаями пневмоний, верифицированных как COVID-19. Это свидетельствует о неполном выявлении COVID-19пневмоний.

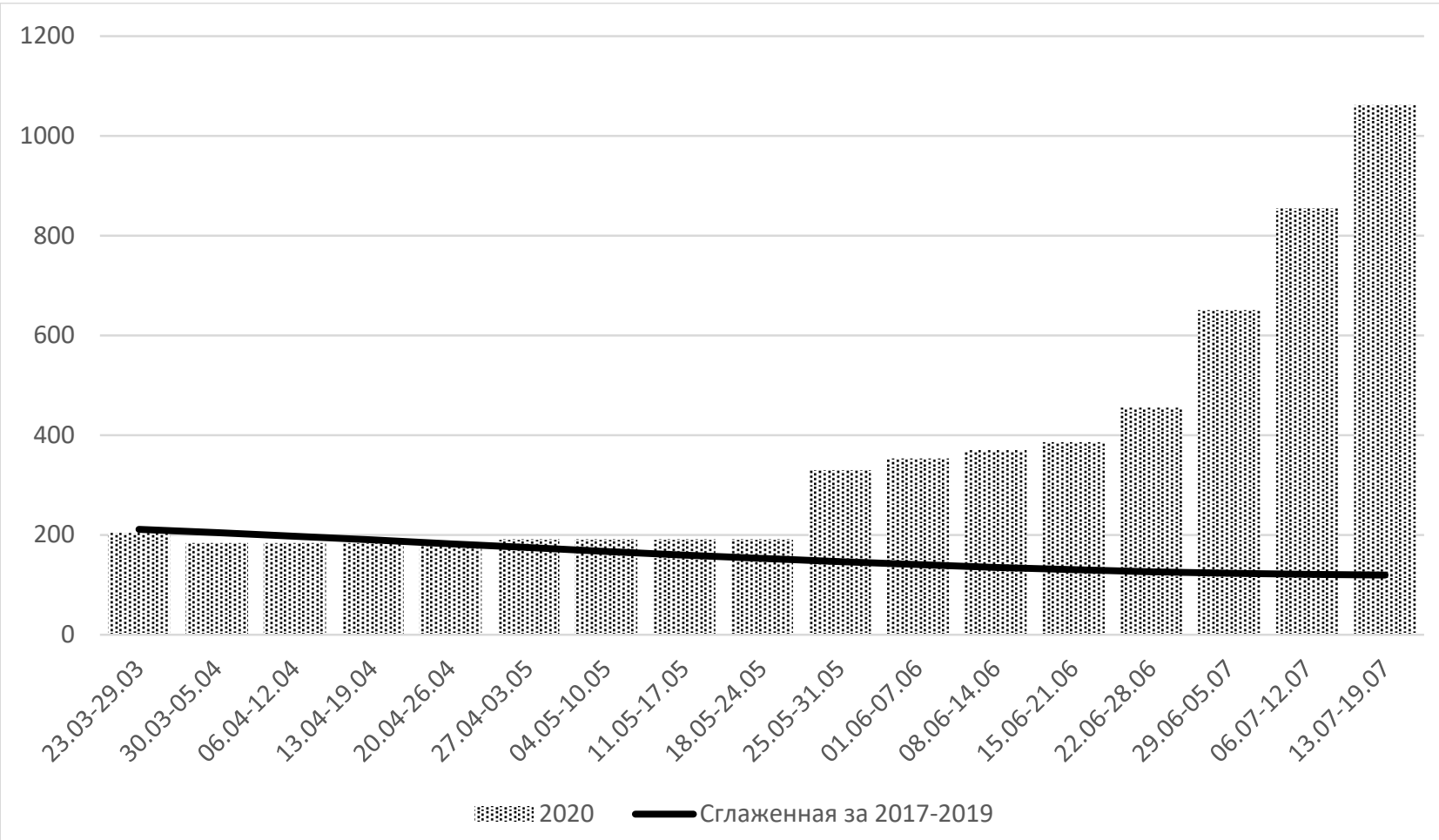

Рис. 6. Внутригодовая динамика регистрации случаев внебольничных пневмоний в 2020 г. сравнении со среднемноголетними показателями за 20172019 гг. в Омской области (абс. по неделям).

Fig. 6. Seasonality of pneumonia cases in Omsk region in 2020 by week compared to 2017-2019 average (abs.).

Для оценки динамики распространения COVID-19 в Омской области в сравнении с г. Москва и Московской областью был построен график кумулятивного числа случаев ${ }^{1}$. Данные по регионам были совмещены во времени по дате регистрации в регионе первых 100 случаев. Для обеспечения наглядности на графике представлены опорные линии, отмечающие удвоение числа случаев каждые пять, семь и десять дней (рис.7). Чем сильнее на графике

\footnotetext{
${ }^{1}$ По данным ресурса «стопкоронавирус.рф».
} 
кривая «изгибается» к горизонту, тем медленнее развивается эпидемический процесс: выраженный изгиб заметен на кривых столичного региона, в то время как кривая Омской области имеет слабо выраженный изгиб, что отражает значительно меньшую скорость снижения трансмиссии COVID-19. Вместе с тем увеличение времени удвоения количества случаев с 7 до 10 дней в Омской области отмечено после 26 дня от точки отсчета, а в Москве - намного позже (78 день после регистрации первых 100 случаев). Среди возможных объяснений причин выявленных различий в характере логарифмических кривых - более раннее относительно начала распространения COVID-19 введение ограничительных мероприятий, но их менее жесткий характер в Омской области по сравнению с г. Москва.

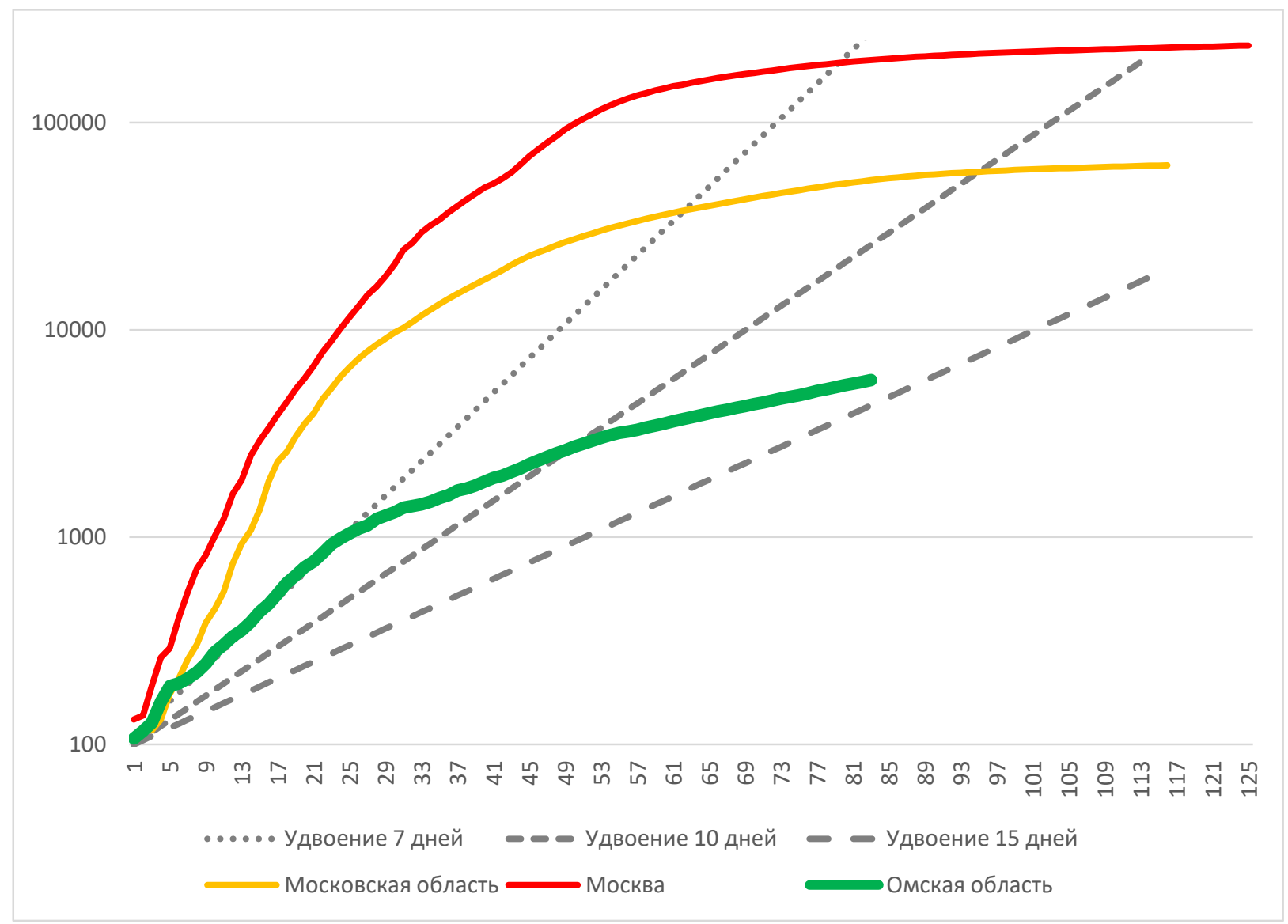

Рис. 7. Динамика роста кумулятивного количества заболевших COVID-19, совмещение на дате регистрации 100 случаев (абс., логарифмическая шкала).

Fig. 7. Cumulative counts of COVID-19 cases, curves combined at 100 cases (abs. log scale). 
Величины базового показателя репродукции, вычисленные на основе экспоненциального темпа прироста кумулятивного числа случаев COVID-19 в течение раннего периода распространения инфекции в Омской области, составили 1,5 и 1,4 при дельта- и экспоненцильно распределённом серийном интервале соответственно. Обе эти оценки свидетельствуют о наличии потенциала COVID-19 к распространению на территории Омской области. Ожидаемый размах эпидемии в случае продолжения действия ограничительных мер может быть в пределах от 50,8\% до 58,0\% заражённого населения, а порог коллективного иммунитета - от $28,6 \%$ до $33,3 \%$ соответственно. В условиях изменяющейся интенсивности противоэпидемических мероприятий реальный размах эпидемии может быть иным: так, по оценкам ВО3 [10] базовый

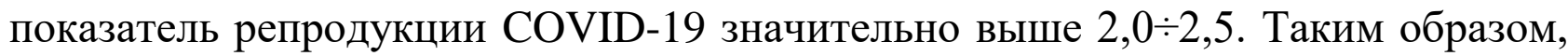
при отсутствии проводимых в Омской области противоэпидемических мероприятий ожидаемый естественный размах эпидемии мог бы составить от $79,7 \%$ до 89,3\% заражённого населения, а порог коллективного иммунитета - от $50,0 \%$ до $60,0 \%$ соответственно.

Средняя оценка Rt на протяжении периода наблюдения составила 1,18 , варьируя от 0,75 до 1,99 (рис. 8), что в целом наглядно демонстрирует существенно, но недостаточно подавляемый системой эпидемиологического надзора потенциал COVID-19 к распространению среди населения Омской области. 


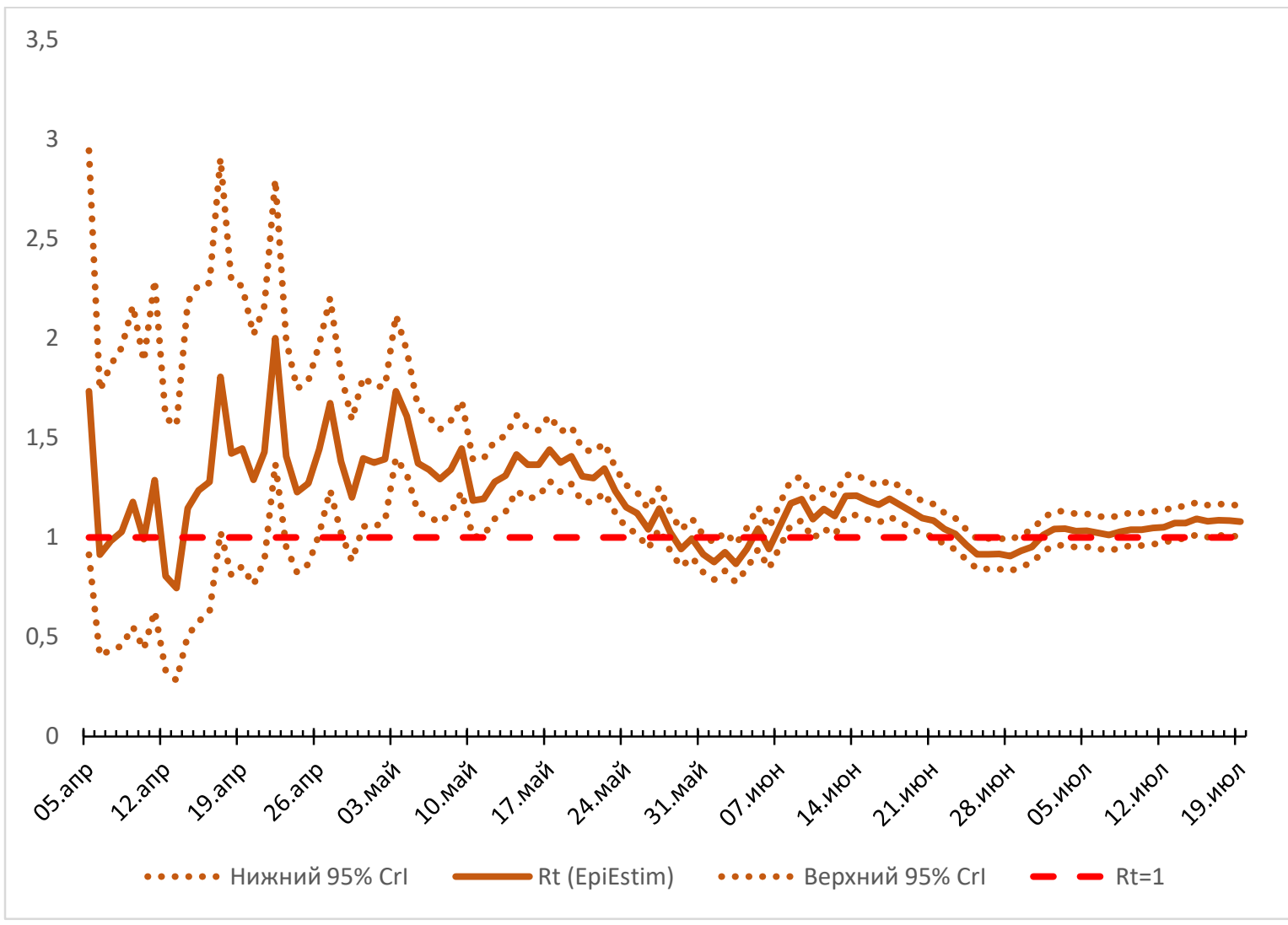

Рис. 8. Оперативная оценка эффективного показателя репродукции COVID-19 в Омской области в период с 05.04.20 по 19.07.20 гг.

Fig. 8. Time-varying reproduction number of COVID-19 in Omsk region during 27.03.20-19.07.20

\section{Заключение}

На фоне проводимых противоэпидемических мероприятий в период с 27 марта по 19 июля 2020 г. экспоненциальный темп прироста кумулятивного количества случаев COVID-19 составлял 6,6\% в сутки, базовый показатель репродукции $\left(\mathrm{R}_{0}\right)$ - 1,4-1,5, эффективный показатель репродукции $\left(\mathrm{R}_{\mathrm{t}}\right)$ - 1,18, порог коллективного иммунитета - 28,6\%. Ожидаемый размах эпидемии в случае продолжения сдерживания эпидемического процесса может достигнуть $58,0 \%$ переболевшего населения.

Потенциал COVID-19 к распространению среди населения Омской области подавлен недостаточно. Уменьшение количества выявляемых вирусоносителей и не полное выявление COVID-19 среди заболевших внебольничными пневмониями создают дополнительные риски для скрытого распространения 
инфекции и осложнения эпидемической ситуации. Сохранение ограничительных мероприятий и превышение порога коллективного иммунитета (28,6\% населения) позволит значительно снизить риски усиления распространения COVID-19 в Омской области.

\section{Литература / References:}

1. WHO. WHO Director-General's opening remarks at the media briefing on COVID19 - 11 March 2020. Available at: https://www.who.int/dg/speeches/detail/who-director-general-s-opening-remarks-atthe-media-briefing-on-covid-19---11-march-2020. Accessed 29.07.20.

2. WHO. Coronavirus disease (COVID-19). Situation Report - 182. Available at: https://www.who.int/docs/default-source/coronaviruse/situationreports/20200720-covid-19-sitrep-182.pdf?sfvrsn=60aabc5c_2. Accessed 29.07.20.

3. Wallinga J, Lipsitch M. How generation intervals shape the relationship between growth rates and reproductive numbers. Proc Biol Sci. 2007;274(1609):599604. doi:10.1098/rspb.2006.3754

4. Nishiura H, Linton NM, Akhmetzhanov AR. Serial interval of novel coronavirus (COVID-19) infections. Int J Infect Dis. 2020; 93: 284-286. doi: 10.1016/j.ijid.2020.02.060

5. Park M, Cook AR, Lim JT et al. A Systematic Review of COVID-19 Epidemiology Based on Current Evidence. J. Clin. Med. 2020, 9, 967.

6. Miller JC. A note on the derivation of epidemic final sizes. Bull Math Biol. 2012; 74(9): 2125-2141. doi:10.1007/s11538-012-9749-6.

7. Rodpothong $\mathrm{P}$, Auewarakul P. Viral evolution and transmission effectiveness. World J Virol. 2012;1(5):131-134. doi:10.5501/wjv.v1.i5.131.

8. Cori A, Ferguson NM, Fraser $\mathrm{C}$ et al. A new framework and software to estimate time-varying reproduction numbers during epidemics. Am J Epidemiol. 2013;178(9):1505-1512. doi:10.1093/aje/kwt133. 
9. Stolwijk AM, Straatman H, Zielhuis GA. Studying seasonality by using sine and cosine functions in regression analysis. J Epidemiol Community Health. 1999;53(4):235-238. doi:10.1136/jech.53.4.235

10. WHO. Coronavirus disease (COVID-19). Situation Report - 46. Available at: https://www.who.int/docs/default-source/coronaviruse/situationreports/20200306-sitrep-46-covid-19.pdf?sfvrsn=96b04adf_4. Accessed 29.07.20. 